\title{
Initial report from the Hunter Outcome Survey
}

\author{
J. Edmond Wraith, $M D^{1}$, Michael Beck, $M D^{2}$, Roberto Giugliani, $M D^{3}$, Joe Clarke, $M D, P h D^{4,5}$, Rick Martin, $M D^{6}$,
} and Joseph Muenzer, $M D^{7}$ on behalf of the HOS Investigators

\begin{abstract}
Purpose: Hunter syndrome (Mucopolysaccharidosis II) is a rare, X-linked disorder of glycosaminoglycan metabolism. It is caused by a deficiency in the lysosomal enzyme iduronate-2-sulfatase, and in affected patients glycosaminoglycan accumulates in lysosomes of various tissues and organs and contributes to the pathophysiology of Hunter syndrome. The Hunter Outcome Survey (HOS) was established to better describe the natural history of this disorder and to evaluate the long-term effect of enzyme replacement therapy. Methods: HOS is an international, multicenter, long-term observational survey that will collect data on participating patients with a confirmed diagnosis of Hunter syndrome. Data will be collected during regular physician examinations and entered into an electronic database. Examples of observations include vital signs, laboratory values, signs and symptoms of organ involvement, and the results of selected functional tests (e.g., audiometry, echocardiogram, joint mobility, etc.). Results: As of May 15, 2007, 263 patients from 16 countries have enrolled in HOS; 24\% of these patients were currently being treated with enzyme replacement therapy. The median age at enrollment was 12.2 years. The median age of onset of symptoms and diagnosis of Hunter syndrome were 1.5 and 3.5 years, respectively. Otitis media and abdominal hernia were the earliest presenting symptoms. Facial dysmorphism and hepatosplenomegaly were demonstrated by $95 \%$ and $89 \%$ of patients, respectively. Conclusions: HOS will be a valuable resource for enhancing the understanding of Hunter syndrome and will provide important information about the natural history of the disease and the role of enzyme replacement therapy in its treatment. Patients and their physicians should be encouraged to participate. Genet Med 2008:10(7):508-516.
\end{abstract}

Key Words: Mucopolysaccharidosis II, Hunter syndrome, enzyme replacement therapy, lysosomal storage disease

Hunter syndrome (mucopolysaccharidosis II, MPS II) is a rare, X-linked disorder of glycosaminoglycan (GAG) catabolism $^{1}$ caused by a deficiency in the activity of the lysosomal enzyme, iduronate-2-sulfatase (I2S). ${ }^{2}$ I2S catalyzes the removal of the sulfate group at the two position of L-iduronic acid residues in dermatan sulfate and heparan sulfate, ${ }^{1}$ and in affected patients these GAG accumulate in lysosomes of many organs and tissues, contributing to the pathologies associated with Hunter syndrome. Hunter syndrome occurs in all ethnic groups with an estimated incidence of 1 in 140,000 to 333,000

\footnotetext{
From the ${ }^{1}$ Willink Biochemical Genetics Unit, Royal Manchester Children's Hospital, Manchester, United Kingdom; ${ }^{2}$ Children's Hospital, University of Mainz, Mainz, Germany; ${ }^{3}$ Medical Genetics Service, Hospital de Clinicas, UFRGS, Porto Alegre, RS, Brazil; ${ }^{4}$ Division of Clinical and Metabolic Genetics, Hospital for Sick Children and University of Toronto, Toronto, Ontario, Canada; ${ }^{5}$ Service de génétique médicale, Centre hospitalier universitaire de Sherbrooke, Sherbrooke, Quebec, Canada; ${ }^{6}$ Pediatric Geneticist at SSM Division of Medical Genetics, Saint Louis University School of Medicine, St. Louis, Missouri; ${ }^{7}$ Department of Pediatrics, Division of Genetics and Metabolism, University of North Carolina at Chapel Hill, Chapel Hill, North Carolina.

J. Edward Wraith, MD, Willink Biochemical Genetics Unit, Royal Manchester Children's Hospital, Manchester, United Kingdom.E-mail:ed.wraith@cmmc.nhs.uk

Disclosure: Drs. Wraith, Beck, Giugliani, Clarke, Martin, and Muenzer have reported receiving honoraria, travel grants, consulting fees, or research grants from Shire Human Genetic Therapies, Inc

Submitted for publication January 7, 2008.

Accepted for publication March 11, 2008.

DOI: 10.1097/GIM.0b013e31817701e6
}

births. ${ }^{3-9}$ Many mutations in the $I 2 S$ gene, located at Xq28, ${ }^{10}$ have been reported, including missense and nonsense mutations, small insertions, and deletions, and rearrangements. ${ }^{11-13}$

Hunter syndrome is a multisystem, multiorgan disorder with a variable age of onset and variable rate of progression. The initial signs of Hunter syndrome emerge in the first decade of life and include coarseness of facial features; enlarged tongue, tonsils, and adenoids resulting in upper respiratory obstruction; and frequent ear infections. ${ }^{14-16}$ Hepatosplenomegaly is common, as is progressive joint and skeletal involvement. The presentation and progression of signs and symptoms are variable. In the most severe phenotype, signs and symptoms occur between 2 and 4 years of age, and progressive neurological involvement is prominent, leading to profound mental impairment. In these patients, death usually occurs in the second decade of life because of respiratory obstruction, neurologic involvement, or cardiac failure. ${ }^{1,14}$ At the opposite end of the phenotype spectrum, patients are spared cognitive involvement but continue to experience all of the somatic signs and symptoms. ${ }^{15}$ In this attenuated phenotype, patients typically survive into adulthood.

Historically, management of Hunter syndrome was palliative and directed at symptoms. Hemopoietic stem cell transplantation (HSCT) has been proposed as a method of providing replacement enzyme, but no controlled studies have been performed. The results of HSCT reported in single case studies 
or in short series of patients have provided no consistent evidence of benefit ${ }^{17-19}$ while showing considerable risk associated with the procedure. ${ }^{19,20}$ The development of recombinant human I2S (Elaprase, idursulfase, Shire Human Genetic Therapies, Inc., Cambridge, MA) has allowed enzyme replacement therapy (ERT) designed to treat Hunter syndrome to be tested in clinical studies. In a Phase II/III double-blind, placebo-controlled trial of idursulfase in 96 patients with Hunter syndrome, patients treated with weekly or every other week doses of $0.5 \mathrm{mg} / \mathrm{kg}$ demonstrated statistically significant improvement compared to placebo in the primary endpoint, a composite variable comprising the sum in ranked changes of distance walked in 6 minutes and ranked changes in percent predicted forced vital capacity. ${ }^{21}$ Idursulfase has received marketing approval in 34 countries as of October 31, 2007, including the United States (in June 2006), European countries, Canada, and Japan.

One of the challenges in the development of effective treatment for rare diseases is the incomplete understanding of the natural history of the disease combined with the inability to conduct sufficiently large and sustained placebo-controlled clinical trials. For example, information about the natural history of Hunter syndrome is limited to a few cross-sectional studies $^{14,15,22,23}$ and case reports. ${ }^{24-27}$ Although with 96 patients, the pivotal clinical trial was the largest placebo-controlled study of the treatment of a lysosomal storage disease conducted to date, the placebo-controlled component lasted only 12 months. In a disease like Hunter syndrome, in which the pathologies take years to develop, 12 months may be a limited time to fully evaluate the effect of ERT. Patient registries or surveys provide an additional source of information on natural history and response to therapy of rare disease. In the remainder of this report, we will describe the Hunter Outcome Survey (HOS) and present the baseline demographics and general disease characteristics as well as the prevalence of cardiovascular and neurological involvement observed in the participating patients.

\section{METHODS}

\section{Patients}

Male and female patients with a biochemically confirmed diagnosis of Hunter syndrome are eligible for enrollment in HOS. The diagnosis was based on a biochemical demonstration of a deficiency of I2S activity or on genetic analysis. Reduced or absent I2S activity (usually measured in peripheral leukocytes) was considered diagnostic of Hunter syndrome in males; however, in male patients without a family history of Hunter syndrome, normal activity of another sulfatase was required to rule out multiple sulfatase deficiency. ${ }^{16}$ Both biochemical and genetic analyses were conducted at a local laboratory rather than at a central site. All patients or their parents or legal representative provided written informed consent for participation in HOS. Data from patients who had died before the initiation of HOS could also be entered into the HOS database. This group was referred to as "Retrospective." The group of patients who were alive at HOS entry was referred to as "Prospective." Both groups were combined for cross-sectional analyses presented in this report.

\section{Site enrollment}

Physicians and centers that care for patients with Hunter syndrome were eligible to join HOS. Each participating center received approval for participating in HOS from their local Institutional Review Board or Ethics committee before enrolling any patients.

\section{Survey design}

The HOS is a global, multi-center, long-term, observational survey that is overseen by national, regional, and global scientific advisory boards. These advisory boards are comprised of participating treating HOS physicians who were elected by all participating HOS physicians. All board members are experienced in the management of Hunter syndrome. These advisory boards supervise the analysis of data collected from national, regional, and global cohorts of patients. HOS is supported by Shire Human Genetic Therapies, Inc. (Cambridge, MA).

HOS was designed to acquire data from Hunter syndrome patients obtained in their usual medical care environment. Data obtained during routine examinations were entered into the HOS database through a secure, computer-based application. The central HOS database is supported by Shire HGT, which was also responsible for training participants at each site in the data entry process. The database is anonymous and confidential; data that could be used to identify patients are accessible only by the patient's HOS physician on his or her local computer.

At entry into HOS, patient demographic information and diagnosis criteria were entered into the HOS database, as was a retrospective medical and surgical history. At the baseline visit and at regular examinations thereafter, clinical and laboratory test data that are part of standard medical care for patients with Hunter syndrome were obtained and entered into the database. Examples included vital signs, developmental milestones (e.g., ability to walk, dress and tie shoes, toilet training, ability to talk, etc), laboratory data (e.g., hematology, blood chemistry, incidence of anti-idursulfase antibodies, and urine GAG levels), and signs and symptoms of Hunter syndrome. Table 1 shows the checklist of the signs and symptoms related to Hunter syndrome that was used when conducting the medical history as well as during each follow-up examination. When entering the observations from an examination, physicians were queried as to the involvement of the 15 organs or body systems shown on this list. If they answered "yes" to any of these general inquiries, they were further queried as to the type of involvement as shown in Table 1. Physicians were requested to enter data in the HOS system as soon as possible after an examination. All therapies and interventions and medications currently being used, including idursulfase, were recorded in the database at each visit. During follow-up, the frequency of examinations was based on the treating physician's standard schedule of care. However, it was recommended that assessments take place at least every 6 months. In addition to the data collected at routine examination visits, physicians were en- 
Table 1

Signs and symptoms checklist used in the Hunter Outcome Survey

1. Head and neck

Facial features consistent with Hunter syndrome

2. Eye

Decreased visual acuity

Corneal opacity

Pale optic disc

3. Mouth

Enlarged tongue

Gingival hypertrophy

Delayed dentition

4. Ear

Acute otitis media

Chronic otitis media

Ear discharge

Ventilation tubes

Tympanic membrane perforation

5. Nose

Nasal obstruction

Rhinorrhea

6. Throat

Enlarged tonsils

7. Chest/Lung

Dyspnea

Chronic cough/bronchitis

Recurrent bronchospasm

Upper airway infection

Lower airway infection

Thoracic deformity

Increased upper airway sounds

8. Cardiovascular

\section{Murmur}

Arrhythmia

Abnormal frequency

Systemic hypertension

Cardiomyopathy

9. Abdomen

Umbilical hernia

Inguinal hernia

10. Gastrointestinal

Decreased appetite

\section{Papilledema}

Retinal degeneration

Strabismus

Abnormal dentition

Dental abscess

Dental caries

Hearing loss-conductive

Hearing loss-sensorineural

Hearing aids

Tinnitus

Vertigo

Nasal polyps

Enlarged adenoids

Wheezing/Rhonchi

Rales/Crepitations

Restrictive airway disease

Obstructive airway disease

Difficulty with intubation

Unable to extubate

Congestive heart disease

Valve disease

Angina pectoris

Myocardial infarction

Peripheral vascular disease

Hepatomegaly

Splenomegaly

Diarrhea
Sleep apnea
Table 1

Continued

\begin{tabular}{ll}
\hline Weight loss & Constipation \\
Abdominal pain & Bowel incontinence \\
11. Genitourinary & \\
Circumcision & Bladder/urinary incontinence \\
Phimosis & Urinary tract infection \\
Undescended testicle &
\end{tabular}

12. Skin

Hunter lesions (pebble lesions)

Naevi

Excessive hair growth

Decubitus ulcers/pressure sores

13. Skeletal

Pain

Scoliosis

Joint stiffness and limited

Claw hands function

Kyphosis/Gibbus

14. Neurological

Hydrocephalus

Fine motor skills impairment

Seizure disorder

Hyperactivity

Abnormal gait

Frequent chewing

Abnormal reflexes

Cognitive problem

Swallowing difficulties

Behavior problem

Carpal tunnel syndrome

15. Psychiatric

Anxiety disorders

Depression

couraged to enter results from a series of predefined additional assessments. These additional assessments are listed in Table 2.

Because HOS was designed to observe patients in their usual care environment, all of the routine and predefined additional assessments (Tables 1 and 2) were made using materials and methods commonly used at the treating physician's office or clinic. No HOS-specific assessment protocols were used. Similarly, the designation of a test result or observation as abnormal was made by the treating physician and was based on commonly accepted criteria that were used at that site.

Table 2

Additional clinical investigations in the Hunter Outcome Survey

Cerebral imaging Joint mobility

Ophthalmology

6-minute walk test

Audiometry

Neurophysiology

Pulmonary function test

Overnight sleep study

Electrocardiogram

Orthopedic imaging

Echocardiogram

Swallowing assessment

Abdominal imaging

Bronchoscopy

These investigations could be performed at the physician's site using equipment and methods commonly employed at that location. 


\section{Statistical methods}

For this report, all available data for each patient as of May 15,2006 , were examined. The age of onset of a sign or symptom associated with Hunter syndrome for each patient was defined as the age at which it was first affirmatively entered into the database, or if present before enrollment, as the age of onset as documented by the medical history. All statistical analyses presented in this report were conducted by Shire HGT under the direction of the HOS advisory boards. However, Shire HGT had no role in the selection of tests to be performed or in the interpretation of the results of those tests. Methods of descriptive statistics were used, including prevalence, mean, median, standard deviation, and percentiles. Percent prevalence of individual characteristics was calculated using the sum of the "yes" and "no" responses as the denominator unless otherwise indicated. To evaluate the prevalence of hypertension, blood pressures were converted to Z scores as described by National High Blood Pressure Education Program Working Group on High Blood Pressure in Children and Adolescents. ${ }^{28}$ Height, weight, and head circumference of HOS participants were compared with age-specific measurements for the general pediatric population. ${ }^{29,30}$ All analyses were done using SAS software (SAS Institute, Cary, NC).

\section{RESULTS}

Enrollment into HOS began in October 2005. A total of 263 patients (262 male, 1 female) from 44 centers in 16 countries had enrolled in HOS as of May 15, 2007. This total included 49 patients who had died before initiation of HOS (the Retrospective group). The baseline characteristics of the patient population are presented in Table 3. At the time of enrollment, 63 patients $(24 \%)$ reported a history of ERT with idursulfase. Only three patients reported a history of bone marrow transplantation. Forty-five patients reported participating in a clinical trial of idursulfase. ${ }^{21}$ Patients were not queried as to their participation in published natural history studies. Genetic information was available for 140 patients. The following types

Table 3

Baseline characteristics of patients enrolled in the Hunter Outcome Survey

\begin{tabular}{|c|c|c|c|}
\hline & Prospective $^{a}$ & Retrospective $^{a}$ & Overall \\
\hline$N$ & 214 & 49 & 263 \\
\hline Age at enrollment or death for retrospective patients (yrs) $\left(n^{b}\right)$ & (214) & $(49)$ & (263) \\
\hline Mean (SD) & $13.1(8.5)$ & $15.3(7.5)$ & $13.5(8.4)$ \\
\hline Median (10th-90th percentile) & $11.1(3.8-24.4)$ & $13.9(8.5-27.8)$ & $12.2(4.2-24.5)$ \\
\hline Age at onset of symptoms (yrs) $\left(n^{b}\right)$ & $(163)$ & $(42)$ & (205) \\
\hline Mean (SD) & $1.9(1.6)$ & $1.4(1.5)$ & $1.8(1.6)$ \\
\hline Median (10th-90th percentile) & $1.5(0.2-4.0)$ & $0.9(0.0-3.0)$ & $1.5(0.1-4.0)$ \\
\hline Age at diagnosis (yrs) $\left(n^{b}\right)$ & $(171)$ & $(41)$ & $(212)$ \\
\hline Mean (SD) & $4.1(3.2)$ & $5.0(6.8)$ & $4.2(4.2)$ \\
\hline Median (10th-90th percentile) & $3.5(1.3-7.0)$ & $3.5(1.5-10.0)$ & $3.5(1.3-8.0)$ \\
\hline \multicolumn{4}{|l|}{ Ethnicity n (\%) } \\
\hline White & $174(81)$ & $44(90)$ & $218(83)$ \\
\hline Black & $14(7)$ & $0(0)$ & $14(5)$ \\
\hline Asian & $6(3)$ & $2(4)$ & $8(3)$ \\
\hline Other or not reported & $20(9)$ & $3(6)$ & $23(9)$ \\
\hline \multicolumn{4}{|l|}{ Family member with Hunter syndrome n (\%) } \\
\hline Yes & $57(27)$ & $10(20)$ & $67(25)$ \\
\hline No & $116(54)$ & $28(57)$ & $144(55)$ \\
\hline Unknown & $41(19)$ & $11(22)$ & $52(20)$ \\
\hline \multicolumn{4}{|l|}{ Country $(\%)$} \\
\hline North America & $39(18)$ & $6(12)$ & $45(17)$ \\
\hline South America & $31(15)$ & $0(0)$ & $31(12)$ \\
\hline Europe & $144(67)$ & $43(88)$ & $187(71)$ \\
\hline
\end{tabular}

a"Prospective" refers to patients who were alive at the time of entry into the Hunter Outcome Survey (HOS), and "Retrospective" refers to patients who had died prior to data entry into the HOS database.

${ }^{b} \mathrm{~N}$ is the number of patients with available data as of May 15, 2007. 
of mutations were reported: complete deletions and large rearrangements $(n=14,10 \%)$, missense $(n=64,46 \%)$, nonsense $(n=39,28 \%)$, splice site $(n=21,15 \%)$, or neutral $(n=$ $2,1.4 \%)$. The one female was in the Retrospective group and had a complete deletion of the gene.

Figure 1, A shows the prevalence (based on the number of "yes" and "no" responses to each feature) of general organ involvement in Hunter syndrome. Specific characteristics of Hunter syndrome (Fig. 1, B) included facial dysmorphism (prevalence $=95 \%$, median age at onset $=2.4$ years), otitis media (74\%, 1.2 years), nasal obstruction (34\%, 2.0 years), enlarged tongue $(70 \%, 3.4$ years), enlarged tonsils or adenoids $(68 \%$, 2.9 years), enlarged liver or spleen (89\%, 2.8 years), abdominal hernia (78\%, 1.3 years), and joint stiffness ( $84 \%, 3.6$ years).

Cross-sectional analysis revealed that average height at first report in HOS was normal up to about age 9 or 10 years (Fig. 2 ), and thereafter was below the third percentile. Similarly, average weight was within the normal range until about age 15 years (Fig. 3). Figure 4 shows the relationship between head circumference and age and demonstrates that Hunter syndrome patients have large heads.

Baseline vital signs are shown in Table 4 and the prevalence of cardiovascular involvement is presented in Table 5. Figure 5 presents the blood pressure $Z$ scores. Hypertension, defined as having a diastolic or systolic blood pressure greater than the 95th percentile of boys of the same age (i.e., $Z$ score $\geq 2^{28}$ ) was present in $33.7 \%$ of the HOS population who had complete blood pressure data (29 of 86 patients). Cardiovascular involvement was reported in $82 \%$ of patients. Heart murmur and valvular involvement were the most common cardiovascular signs found in this population.

Neurological involvement was common and was found in $84 \%$ of patients (Table 6 ). The most common symptoms of neurological involvement were behavioral and cognitive prob-

\section{A}

\section{Organ System}

Abdomen
Head and Neck
Skeletal
Ear
Mouth
Neurological
Chest and Lungs
Cardiovascular
Throat
Skin
Nose
Gastrointestinal
Eyes
Genitourinary
Psychiatric
Other

Other

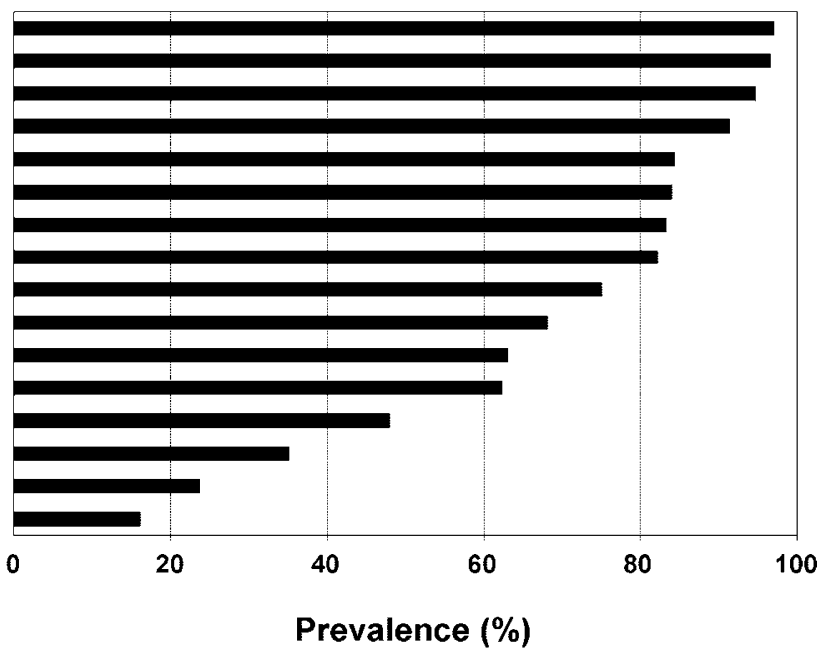

Prevalence

Feature

Cardiac valve disease

Kyphosis/scoliosis

Joint stiffness

Enlarged tongue

Enlarged tonsils/adenoids

Enlarged liver/spleen

Facial features

Nasal obstruction

Hernia

Otitis

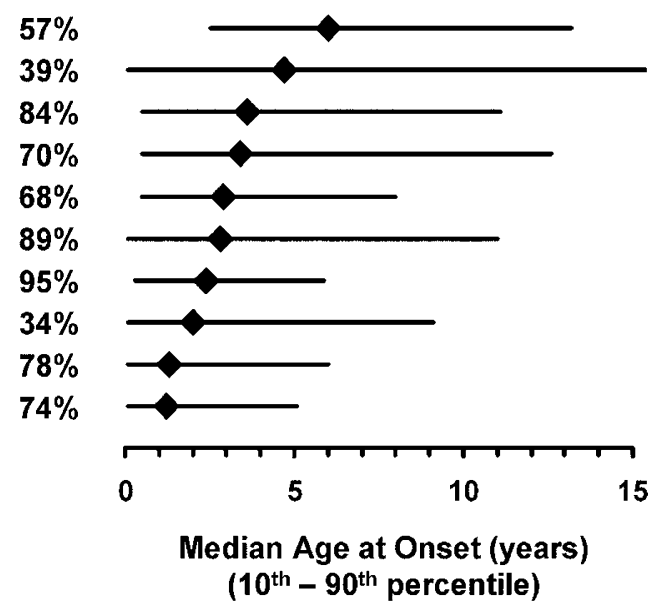

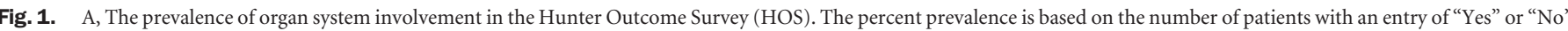
to the question of general organ system involvement shown in Table 1. B, Prevalence of specific organ involvement in HOS. 


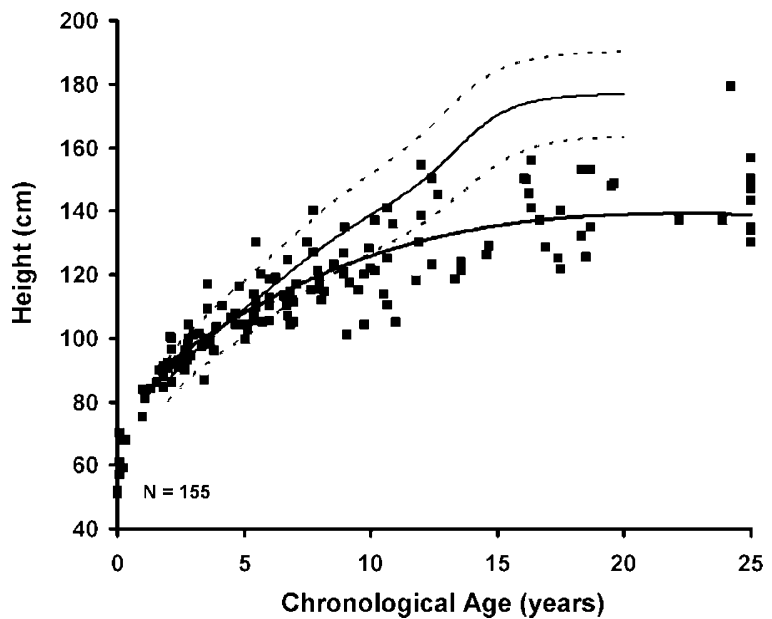

Fig. 2. Relationship between age and height in the Hunter Outcome Survey. The bold solid line is the cubic regression fit through the data points. The other solid (mean) and dotted lines (3rd and 97th percentile) show the relationship of age and height in boys from the National Health and Nutrition Examination Survey. ${ }^{29}$

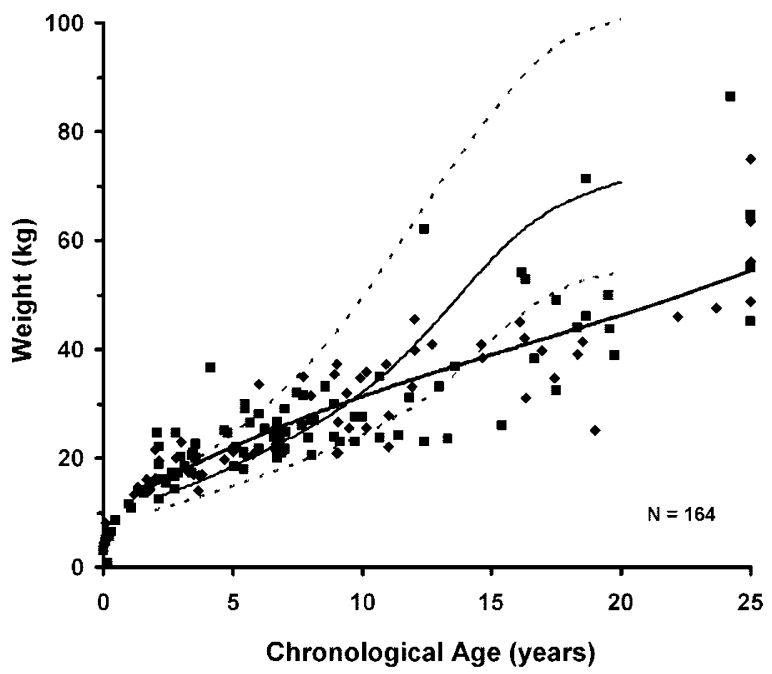

Fig. 3. Relationship between age and weight in the Hunter Outcome Survey. The bold solid line is the cubic regression fit through the data points. The other solid (mean) and dotted lines (3rd and 97th percentile) show the relationship of age and weight in boys from the National Health and Nutrition Examination Survey. ${ }^{29}$

lems, which were found in $36 \%$ and $37 \%$ of patients and had a median age at onset of 3.7 and 3.2 years, respectively.

The age of walking was reported for 97 patients and averaged $1.19 \pm 0.38$ years (median $=1.08$ years, 10 th -90 th percentile $=0.9-1.5$ years). In 37 patients, the average age of achieving toilet training was $3.25 \pm 1.96$ years (median $=3.0$ years, 10th-90th percentile $=1.8-5.0$ years). In patients older than 5 years, toilet training was reported in 57 of 87 patients $(66 \%)$. Seven patients were reported as having regressed from having achieved toilet training to having lost this ability.

\section{DISCUSSION}

With 263 patients currently enrolled, HOS represents the largest group of Hunter syndrome patients yet to be studied together. Since the initial report by Hunter in $1917,{ }^{31}$ the

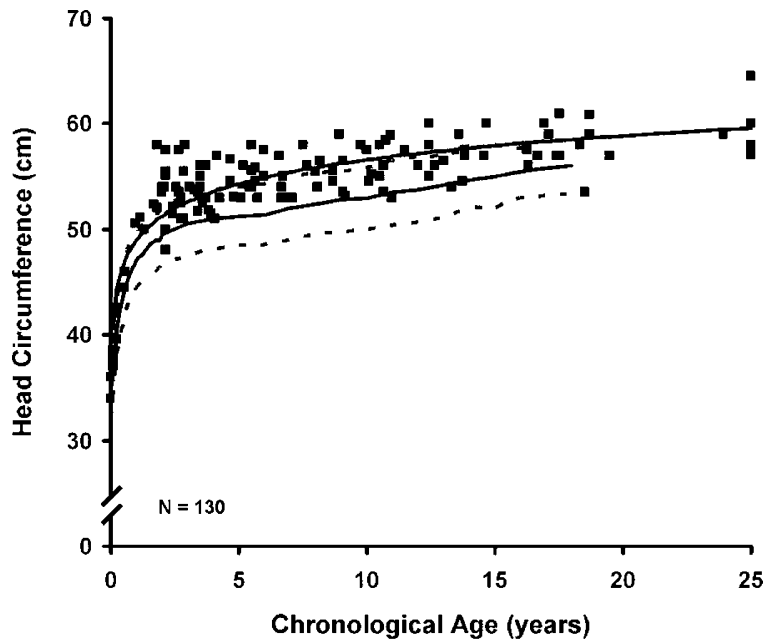

Fig. 4. Head circumference of patients in the Hunter Outcome Survey. The bold solid line is the cubic regression fit through the data points. The other solid (mean) and dotted lines $( \pm 2$ SD) show the relationship of age and head circumference in boys from Nellhaus. ${ }^{30}$

Table 4

Baseline vital signs in the Hunter Outcome Survey

\begin{tabular}{lcc}
\hline Parameter & $N^{a}$ & Mean (10th-90th percentile) \\
\hline Heart rate (beats/min) & 130 & $96.4(76.5-116.0)$ \\
Systolic blood pressure (mm Hg) & 126 & $113.6(96.0-132.0)$ \\
Diastolic blood pressure (mm Hg) & 124 & $67.8(50.0-87.0)$ \\
\hline
\end{tabular}

${ }^{a} \mathrm{~N}$ is the number of patients with available data as of May 15, 2007.

Table 5

Prevalence of cardiovascular disease in the Hunter Outcome Survey

\begin{tabular}{lcc}
\hline & $\begin{array}{c}\text { Prevalence of cardiovascular } \\
\text { involvement } n(\%)^{a}\end{array}$ & $\begin{array}{c}\text { Median age at } \\
\text { onset (yrs) }\end{array}$ \\
\hline $\begin{array}{l}\text { Any cardiovascular signs } \\
\text { or symptoms }\end{array}$ & $166(82)$ & - \\
Murmur & $125(62)$ & 5.8 \\
Tachycardia & $15(7)$ & 11.3 \\
Bradycardia & $5(2)$ & 13.9 \\
Arrhythmia & $9(4)$ & 6.3 \\
Hypertension & $12(6)$ & 11.4 \\
Cardiomyopathy & $17(8)$ & 4.8 \\
Congestive heart failure & $8(4)$ & 8.9 \\
Cardiac valve disease & $115(57)$ & 6.1 \\
Angina & $0(0)$ & - \\
Myocardial infarction & $1(0.5)$ & 44.9 \\
Peripheral vascular disease & $4(2)$ & 9.3 \\
\hline
\end{tabular}

"Percent prevalence based on the total number of patients with a "Yes" or "No" recorded for the question about cardiovascular involvement as of May 15, 2007 $(N=202)$. These designations are based on commonly accepted criteria used at the treating physician's site.

knowledge about Hunter syndrome and its progression has been based primarily on several cross-sectional and retrospective studies ${ }^{14,15,23}$ and numerous case reports. ${ }^{24-27}$ Although these cross-sectional studies have been useful in describing the 

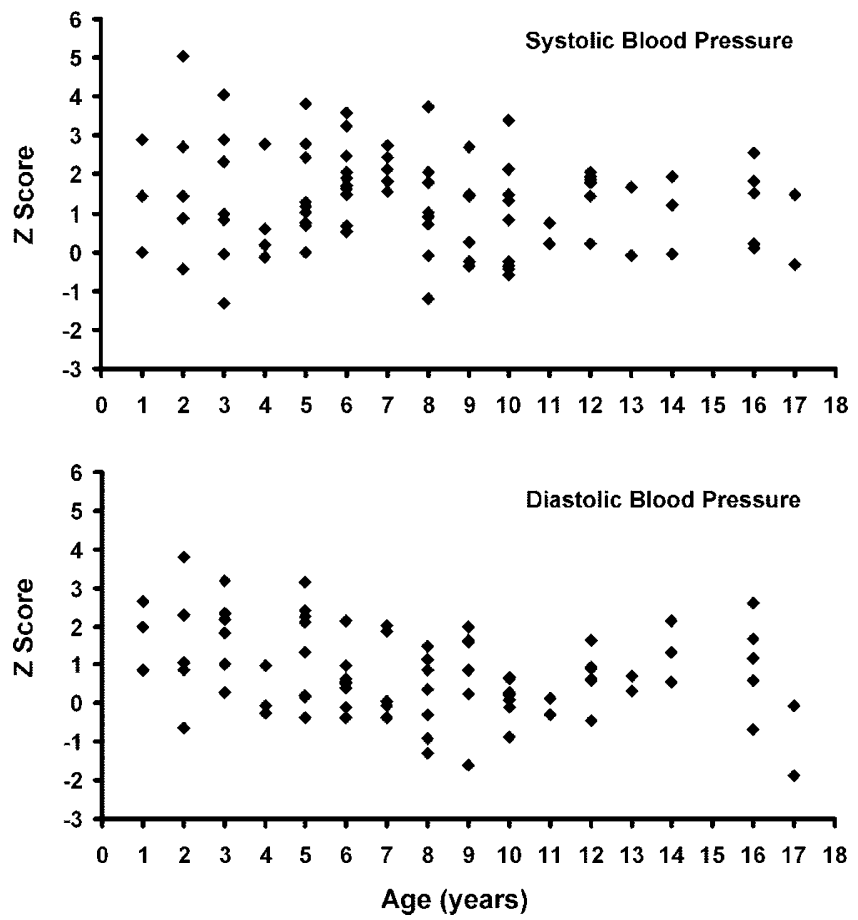

Fig. 5. Blood pressure Z scores for patients in the Hunter Outcome Survey. The Z score indicates where a patient's blood pressure falls in relation to those in otherwise healthy children of the same age. A Z score of 2 means that the blood pressure was 2 standard deviations above the population mean. Hypertension was defined as having a $\mathrm{Z}$ score $\geq 2$ for diastolic blood pressure, systolic blood pressure, or both. Z scores were calculated as described by the National High Blood Pressure Program Working Group on High Blood Pressure in Children and Adolescents. ${ }^{28}$

Table 6

Prevalence of neurological involvement in the Hunter Outcome Survey

Prevalence of neurological Median age at involvement $n(\%)^{a} \quad$ onset (yrs)

\begin{tabular}{lcc}
\hline Any neurological involvement & $173(84)$ & \\
Hydrocephalus & $34(17)$ & 5.8 \\
History of seizure & $37(18)$ & 9.3 \\
Behavior problems & $75(36)$ & 3.7 \\
Cognitive problems & $76(37)$ & 3.2 \\
Hyperactivity & $64(31)$ & 3.5 \\
Gait problems & $69(33)$ & 5.5 \\
Decreased muscle strength & $31(15)$ & 11.2 \\
Decreased sensation & $8(4)$ & 10.9 \\
Difficulty swallowing & $55(27)$ & 8.9 \\
Chewing problems & $26(13)$ & 6.8 \\
Carpal tunnel syndrome & $52(25)$ & 7.9 \\
Fine motor skill impairment & $69(33)$ & 4.0 \\
\hline
\end{tabular}

${ }^{a}$ Percent prevalence is based on the total number of patients with a "Yes" or "No" recorded for the question about neurological involvement as of May 15, $2007(N=$ 206). These signs and symptoms could be self-reported, reported by parents or guardians, or be the result of neurological evaluation by the physician. phenotype of Hunter syndrome at particular time points, they lacked longitudinal follow-up, and thus, provide limited information about the progression of the disease. HOS is structured to provide serial follow-up and will add to the understanding of the progression of Hunter disease as the follow-up time increases.

This initial report of HOS is a cross-sectional description of the signs and symptoms of Hunter syndrome and in general confirms the previous studies. Linear growth in the HOS cohort is similar to that reported by Young and Harper for both attenuated ${ }^{15}$ and severely affected ${ }^{14}$ patients. Similar growth parameters were also recently reported for a group of 77 Hunter syndrome patients of mixed phenotypes. ${ }^{23}$

Cardiovascular involvement is common in the HOS cohort, in which it was reported in $82 \%$ of patients. This prevalence is similar to that reported by Schwartz and colleagues who found some cardiac abnormality in 33 of 38 patients $(87 \%)$ who had an echocardiographic examination. ${ }^{23}$ Similarly, Young and Harper found evidence of cardiac disease in $91 \%$ of patients with an attenuated phenotype ${ }^{15}$ and in more than $50 \%$ of patients with a severe phenotype. ${ }^{14}$ The high incidence of cardiac involvement is important because cardiac causes are important contributors to early mortality in both attenuated and severe Hunter syndrome. An unexpected finding was the high prevalence of age-inappropriate blood pressure. In this study population, hypertension was present in $33.7 \%$ of the patients. High blood pressure is known to contribute to cardiovascular and kidney disease in adults, ${ }^{32}$ but it is not known whether it contributes to the cardiovascular involvement in Hunter syndrome.

In the HOS cohort, some form of neurological involvement was found in $84 \%$ of patients (Table 6). Prominent neurological involvement, progressing to severe mental impairment, is what defines the severe phenotype of Hunter syndrome. Many of the aspects of neurological involvement listed in Table 6 are not likely to be an indicator of the severe phenotype, because they describe systemic involvement (e.g., carpel tunnel syndrome) or may be the result of nonneurologic skeletal problems (e.g., gait disturbances, coordination and joint restrictions). In other studies, the prevalence of behavioral problems was more common in patients with the severe phenotype than in patients with the attenuated phenotype, ${ }^{14,15,23}$ but behavioral problems are reported in patients with both phenotypes. ${ }^{22}$

Early motor development appeared to be relatively normal in this population. For example, the average reported age of walking was 1.19 years (about 14.3 months). This age is similar to that reported by WHO Multicenter Growth Reference Study Group, who found that the average age of walking to be about 13 months with a 99\% confidence interval of 8.2-17.6 months. ${ }^{33}$ Similarly, the achievement of toilet training occurs within the normal range. ${ }^{34}$ However, in HOS, toilet training was reported in $66 \%$ of patients older than 5 years, and 7 patients were reported as having regressed from having achieved toilet training to having lost this ability.

Patient registries or surveys are important tools for understanding the natural history of rare diseases and for evaluating 
the effect of various management strategies. For example, other patient surveys are currently documenting both the natural history of rare genetic metabolic disorders as well as the impact of ERT on their progression. ${ }^{35-43}$ HOS will be a valuable resource for enhancing the understanding of Hunter syndrome. Not only will it provide valuable information about the natural history of the disease, but as longitudinal follow-up develops, it may allow the identification of early signs and symptoms that are risk factors for the severe phenotype. The ability to identify early those children who will progress to profound neurological involvement is an important aspect of genetic counseling, because a family's mutation usually results in a similar phenotype. In addition, HOS will be an important tool for the evaluation of the efficacy of ERT with idursulfase when used outside of the clinical trial environment, with the ultimate goal of improving the treatment of patients with this devastating, chronic, and progressive disease. Thus, it is important to encourage all physicians and health-care providers who manage Hunter syndrome patients and their families to participate in HOS, regardless of whether the patient is actively being treated with idursulfase.

\section{ACKNOWLEDGMENTS}

The Hunter Outcome Survey is supported by Shire HGT, Inc., which is responsible for maintaining the central database and for performing statistical analyses at the request of the HOS advisory board. Shire HGT had no role in the interpretation of data. Editorial assistance to the authors was provided by Edward Weselcouch, $\mathrm{PhD}$ and was paid for by Shire HGT, Inc.

The following physicians have contributed patient data as of May 15, 2007: Thomas Kroepfl, Barbara Plecko, Michaela Brunner-Krainz: Graz, Austria; Olaf Bodamer, Rene Ratschmann, Thomas Moritz, Christina Hung: Vienna, Austria; Linda De Meirleir: Brussels, Belgium; Dantón Melgar: Santa Cruz de la Sierra, Bolivia; Roberto Giugliani, Taiane Vieira: Porto Alegre, Brazil; Dafne Horovitz: Rio de Janeiro, Brazil; Joe Clarke: Toronto, Canada; Jiri Zeman: Prague, Czech Republic; Allan Meldgaard Lund: Copenhagen, Denmark; Nathalie Guffon: Lyon, France; Michael Beck, Gudrun Schulze Frenking: Mainz, Germany; Nicole Muschol, Kurt Ullrich, Ilona Berkau: Hamburg, Germany; Dimitrios Zafeiriou: Thessaloniki, Greece; Zsuzsanna Almássy: Budapest, Hungary; Orazio Gabrielli: Ancona, Italy; Alessandro Cicognani: Bologna, Italy; Maurizio Scarpa: Padova, Italy; Roberta Ricci: Rome, Italy; Cecília Bonilla: Lima, Peru; Peter Novikov: Moscow, Russia; Guillem Pintos: Badalona, Spain; Enrique Galán: Badajoz, Spain; Mireia del Toro, Merce Pineda: Barcelona, Spain; Milagros Marti Herrero: Las Palmas, Spain; Pilar Munguira: Linares, Spain; Luis González Gutiérrez-Solana: Madrid, Spain; Rosario Domingo: Murcia, Spain; Begoña de Azua: Palma de Mallorca, Spain; Jaime Dalmau: Valencia, Spain; José Manuel Muro: Valladolid, Spain; Antonio Baldellou, Juan Pérez Calvo: Zaragoza, Spain; Nils Nilsson: Halmstad, Sweden; Dominiki Papadopoulou: Lund, Sweden; Gunilla Malm: Stockholm, Sweden; Philippa Desveaux, Uma Ramaswami: Cambridge, United Kingdom; Simon Jones, Edmond Wraith:
Manchester, United Kingdom; Paul Fernhoff: Atlanta, Georgia; Joseph Muenzer: Chapel Hill, North Carolina; Barbara Burton: Chicago, Illinois; Janet Thomas: Denver, Colorado; Robert Greenstein: Hartford, Connecticut; Parul Jayakar: Miami, Florida; Chester Whitley: Minneapolis, Minnesota; Paul Harmatz: Oakland, California; Kirk Aleck: Phoenix, Arizona.

The investigators would like to thank the MPS II patients and their families for their participation in HOS. In addition, the MPS Brazil Network provided valuable help in contacting patients.

\section{References}

1. Neufeld EF, Muenzer J. The mucopolysaccharidoses. In: Scriver CR, editor. The metabolic and molecular bases of inherited disease. New York: McGraw-Hill, 2001: 3421-3452.

2. Bach G, Eisenberg F Jr, Cantz M, Neufeld EF. The defect in the Hunter syndrome: deficiency of sulfoiduronate sulfatase. Proc Natl Acad Sci U S A 1973;70: 2134-2138.

3. Baehner F, Schmiedeskamp C, Krummenauer F, et al. Cumulative incidence rates of the mucopolysaccharidoses in Germany. J Inherit Metab Dis 2005;28:1011-1017.

4. Meikle PJ, Hopwood JJ, Clague AE, Carey WF. Prevalence of lysosomal storage disorders. JAMA 1999;281:249-254.

5. Poorthuis BJ, Wevers RA, Kleijer WJ, et al. The frequency of lysosomal storage diseases in The Netherlands. Hum Genet 1999;105:151-156.

6. Nelson J. Incidence of the mucopolysaccharidoses in Northern Ireland. Hum Genet 1997;101:355-358.

7. Nelson J, Crowhurst J, Carey B, Greed L. Incidence of the mucopolysaccharidoses in Western Australia. Am J Med Genet 2003;123:310-313.

8. Lowry RB, Renwick DH. Relative frequency of the Hurler and Hunter syndromes. N Engl J Med 1971;284:221-222.

9. Applegarth DA, Toone JR, Lowry RB. Incidence of inborn errors of metabolism in British Columbia, 1969-1996. Pediatrics 2000;105:e10.

10. Wilson PJ, Suthers GK, Callen DF, et al. Frequent deletions at Xq28 indicate genetic heterogeneity in Hunter syndrome. Hum Genet 1991;86:505-508.

11. Kim CH, Hwang HZ, Song SM, et al. Mutational spectrum of the iduronate 2 sulfatase gene in 25 unrelated Korean Hunter syndrome patients: identification of 13 novel mutations. Hum Mutat 2003;21:449-450.

12. Lissens W, Seneca S, Liebaers I. Molecular analysis in 23 Hunter disease families. J Inherit Metab Dis 1997;20:453-456.

13. Vafiadaki E, Cooper A, Heptinstall LE, Hatton CE, Thornley M, Wraith JE. Mutation analysis in 57 unrelated patients with MPS II (Hunter's disease). Arch Dis Child 1998;79:237-241

14. Young ID, Harper PS. The natural history of the severe form of Hunter's syndrome: a study based on 52 cases. Dev Med Child Neurol 1983;25:481-489.

15. Young ID, Harper PS. Mild form of Hunter's syndrome: clinical delineation based on 31 cases. Arch Dis Child 1982;57:828-836.

16. Martin R, Beck M, Giugliani R, Harmatz P, Munoz MV, Muenzer J. Recognition and diagnosis of mucopolysaccharidosis II (Hunter syndrome). Pediatrics 2008;121: e377-e386.

17. Coppa GV, Gabrielli O, Zampini L, et al. Bone marrow transplantation in Hunter syndrome (mucopolysaccharidosis type II): two year follow-up of the first Italian patient and review of the literature. Ped Med Chir 1995;17:227-235.

18. McKinnis EJ, Sulzbacher S, Rutledge JC, Sanders J,Sanders J, Scott CR. Bone marrow transplantation in Hunter syndrome. J Pediatr 1996;129:145-148.

19. Vellodi A, Young E, Cooper A, Lidchi V, Winchester B, Wraith JE. Long-term follow-up following bone marrow transplantation for Hunter disease. J Inherit Metab Dis 1999;22:638-648.

20. Peters C, Krivit W. Hematopoietic cell transplantation for mucopolysaccharidosis IIB (Hunter syndrome). Bone Marrow Transplant 2000;25:1097-1099.

21. Muenzer J, Wraith JE, Beck M, et al. A phase II/III clinical study of enzyme replacement therapy with idursulfase in mucopolysaccharidosis II (Hunter syndrome). Genet Med 2006;8:465-473.

22. Young ID, Harper PS. Psychosocial problems in Hunter's syndrome. Child Care Health Dev 1981;7:201-209.

23. Schwartz IV, Ribeiro MG, Mota JG, et al. A clinical study of 77 patients with mucopolysaccharidosis type II. Acta Paediatr Suppl 2007;96:63-70.

24. Young ID, Harper PS. Long-term complications in Hunter's syndrome. Clin Gene 1979;16:125-132.

25. Morehead JM, Parsons DS. Tracheobronchomalacia in Hunter's syndrome. Int J Pe diatr Otorhinolaryngol 1993;26:255-261. 


\section{Wraith et al.}

26. Benson PF, Button LR, Fensom AH, Dean MF. Lumbar kyphosis in Hunter's disease (MPS II). Clin Genet 1979;16:317-322.

27. Brama I, Gay I, Feinmesser R, Springer C. Upper airway obstruction in Hunter syndrome. Int J Pediatr Otorhinolaryngol 1986;11:229-235.

28. National High Blood Pressure Education Program. The fourth report on the diagnosis, evaluation, and treatment of high blood pressure in children and adolescents. Pediatrics 2004;114:555-576.

29. Kuczmarski RJ, Ogden CL, Guo SS, et al. 2000 CDC Growth Charts for the United States: methods and development. Vital Health Stat 2002;11:1-190.

30. Nellhaus G. Head circumference from birth to eighteen years. Practical composite international and interracial graphs. Pediatrics 1968;41:106-114.

31. Hunter C. A rare disease in two brothers. Proc R Soc Med 1917;10:104-116.

32. Chobanian AV, Bakris GL, Black HR, et al. The seventh report of the Joint National Committee on Prevention, Detection, Evaluation, and Treatment of High Blood Pressure: The JNC 7 Report. JAMA 2003;289:2560-2571.

33. Who Multicentre Growth Reference Study Group. WHO Motor Development Study: windows of achievement for six gross motor development milestones. Acta Paediatr Suppl 2006;450:86-95.

34. Schum TR, Kolb TM, McAuliffe TL, Simms MD, Underhill RL, Lewis M. Sequential acquisition of toilet-training skills: a descriptive study of gender and age differences in normal children. Pediatrics 2002;109:E48.

35. Schwarting A, Dehout F, Feriozzi S, et al. Enzyme replacement therapy and renal function in 201 patients with Fabry disease. Clin Nephrol 2006;66:77-84.
36. Linhart A, Kampmann C, Zamorano JL, et al. Cardiac manifestations of AndersonFabry disease: results from the international Fabry outcome survey. Eur Heart J 2007;28:1228-1235.

37. Eng CM, Fletcher J, Wilcox WR, et al. Fabry disease: Baseline medical characteristics of a cohort of 1765 males and females in the Fabry Registry. J Inherit Metab Dis 2007;30:184-192.

38. Pastores GM, Arn P, Beck M, et al. The MPS I registry: design, methodology, and early findings of a global disease registry for monitoring patients with Mucopolysaccharidosis Type I. Mol Genet Metab 2007;91:37-47.

39. Kaplan P, Andersson HC, Kacena KA, Yee JD. The clinical and demographic characteristics of nonneuronopathic Gaucher disease in 887 children at diagnosis. Arch Pediatr Adolesc Med 2006;160:603-608

40. Sobreira E, Pires RF, Cizmarik M, Grabowski GA. Phenotypic and genotypic heterogeneity in Gaucher disease type 1: a comparison between Brazil and the rest-ofthe-world. Mol Genet Metab 2007;90:81-86.

41. Weinreb NJ, Aggio MC, Andersson HC, Andria G, et al. Gaucher disease type 1: revised recommendations on evaluations and monitoring for adult patients. Semin Hematol 2004;41:15-22.

42. Wenstrup RJ, Kacena KA, Kaplan P, et al. Effect of enzyme replacement therapy with imiglucerase on BMD in type 1 Gaucher disease. J Bone Miner Res 2007;22:119-126.

43. Charrow J, Dulisse B, Grabowski GA, Weinreb NJ. The effect of enzyme replacement therapy on bone crisis and bone pain in patients with type 1 Gaucher disease. Clin Genet 2007;71:205-211. 